\title{
APLIKASI METODE LEAN UNTUK MENDETEKSI DAN MEREDUKSI PEMBOROSAN PADA SISTEM PRODUKSI INSTALASI PENJERNIHAN AIR MINUM NGAGEL III (STUDI KASUS PDAM KOTA SURABAYA)
}

\author{
I.G.A Sri Deviyanti \\ Jurusan Teknik Industri \\ Universitas WR.Supratman Surabaya \\ Email:
}

\begin{abstract}
ABSTRAKSI
$\mathrm{P}$ erusahaan Daerah Air Minum (PDAM) adalah salah satu perusahaan daerah dengan kegiatan pokok melayani dan menyediakan air bersih kepada masyarakat melalui sistim perpipaan. Perusahaan Daerah Air Minum kota Surabaya merupakan perusahaan pemerintah yang mempunyai tanggung jawab terhadap pengelolaan air untuk dikonsumsi masyarakat Surabaya. Agar masyarakat dapat menikmati air bersih yang terjamin kualitas dan kuantitasnya Perusahaan Daerah Air Minum harus meningkatkan performansinya dan salah satu caranya adalah dengan melakukan effisiensi yaitu dengan mengurangi aktivitas non value added yang sebenarnya merupakan pemborosan. Metode Lean merupakan sebuah filosofi yang mencoba untuk mengeliminir segala bentuk pemborosan yang terjadi dalam aliran nilai. Penelitian diawali dengan memahami karakteristik system secara umum dan menggambarkan Big Picture Mapping. Selanjutnya mengaplikasikan waste workshop untuk mengidentifikasikan waste yang terjadi dengan menggunakan tool yang terpilih. Proses pemilihan tool ini dengan menggunakan metode Value Stream Analysis Tool untuk mendapatkan tool mana yang tepat dalam proses mapping tool yang terpilih adalah process activity mapping. Pemborosan yang terjadi selanjutnya di analisa untuk mencari akar penyebab pemborosan. Bentuk rekomendasi yang diberikan dalam penelitian ini ditujukan untuk mereduksi akar penyebab pemborosan tersebut.
\end{abstract}

\section{Kata kunci : Waste, Big Picture Mapping, Value Stream Analysis Tool}

\section{PENDAHULUAN}

Perusahaan Daerah Air Minum (PDAM) yang merupakan salah satu perusahaan daerah dengan kegiatan pokok adalah melayani dan menyediakan air bersih kepada masyarakat melalui sistim perpipaan. PDAM Surabaya memiliki lima instalasi penjernihan air untuk mencukupi kebutuhan masyarakat Surabaya, salah satu instalasi yang menjadi obyek adalah Instalasi Penjernihan Air Minum (IPAM) III Ngagel Surabaya. Masalah utama untuk air minum meliputi kuantitas air yang sudah tidak mampu memenuhi kebutuhan manusia yang terus meningkat, dan kualitas air untuk keperluan domestik terus menurun serta kontiunitas produksi air yang tidak pasti.

Air sebagai komponen sumber daya alam yang sangat penting maka harus dipergunakan untuk sebesar-besar kemakmuran rakyat. Agar air dapat bermanfaat secara lestari dan dapat menunjang pembangunan yang berkelanjutan maka dalam pelaksanaan pembangunan perlu dilakukan pengelolaan kualitas air (Peraturan Daerah Kota Surabaya, 2004). Instalasi Penjernihan Ngagel III di bangun pada tahun 1982 dan permasalahan yang dihadapi sekarang adalah terjadi permasalahan pada proses produksi yang disebabkan oleh adanya aktivitas non value added atau sering disebut dengan pemborosan (Waste).

Berangkat dari masalah ini perlu diadakan perubahan metode produksi menjadi lean Production. Dipilihnya metode Lean Production, karena dapat memberikan kerangka kerja yang memfokuskan pada Value, dan meminimasi pemborosan dan memenuhi kebutuhan costumer (Taylor, 2001).

\section{TINJAUAN PUSTAKA}

\section{Big Picture Mapping}

Big Picture Mapping adalah suatu tool yang diadopsi dari system produksi Toyota yang dapat digunakan untuk menggambarkan suatu system secara keseluruhan beserta aliran nilai (value stream ) yang terdapat dalam perusahaan. Sehingga nantinya diperoleh gambaran mengenai aliran informasi dan aliran fisik dari system yang ada, mengidentifikasi dimana terjadinya waste, serta menggambarkan lead 
time yang dibutuhkan berdasar dari masing-masing karakteristik proses yang terjadi. (Taylor,2001)

\section{Diagram Tulang Ikan ( Fishbone Diagram)}

Diagram ini disebut juga diagram tulang ikan karena bentuknya seperti ikan. Selain itu juga disebut dengan diagram Ishikawa karena yang menemukan adalah Prof. Ishikawa yang berasal dari jepang. Diagram ini digunakan untuk menganalisa dan menemukan factor-faktor yang berpengaruh secara signifikasi dalam menentukan karakteristik kualitas output kerja, mencari penyebab-penyebab yang sesungguhnya dari suatu masalah. Penyebab permasalahan dapat dijabarkan dalam beberapa hal utama antara lain : manusia, mesin atau peralatan lain, material, metode kerja, dan lingkungan kerja. (Taylor,2001)

\section{Konsep Dasar Lean}

Pada dasarnya konsep lean adalah upaya terus - menerus untuk menghilangkan pemborosan dan meningkatkan nilai tambah produk (barang atau jasa ) agar memberikan nilai tambah kepada pelanggan. Konsep Lean ini diprakarsai oleh system produksi Toyota dijepang. Konsep Lean dirintis dijepang oleh Taichi Ohno dan Sensei Sheigo Shingo Ada 7 macam pemborosan yang didefinisikan menurut Taichi Ohno dan Shigeo Shingo (Pujawan, 2005) yaitu:

1. Produksi berlebih (Overproduction)

2. Cacat (Defects)

3. Waktu tunggu (Waiting)

4. Gerakan yang tidak perlu (Unnecessary Motion)

5. Proses yang tidak sesuai (Inappropriate Processing)

6. Transportasi (Transportation)

7. Persediaan yang tidak perlu (Unnecessary Inventory)

\section{VALSAT (value stream analysis tool)}

Pada prinsipnya value stream analysis tool digunakan sebagai alat Bantu untuk memetakan secara detail aliran nilai (value stream) yang berfokus pada value adding process. Detailmapping ini kemudian dapat digunakan untuk menemukan penyebab waste yang terjadi. (Taylor,2001) Terdapat tujuh tools yang paling umum digunakan dalam detail mapping value stream, ketujuh tools tersebut adalah :
1. Process activity mapping

2. Supply chain response matrix

3. Production variety funnel

4. Quality filter mapping

5. Demand amplification mapping

6. Decision point analysis

7. Physical structure mapping

\section{METODE PENELITIAN}

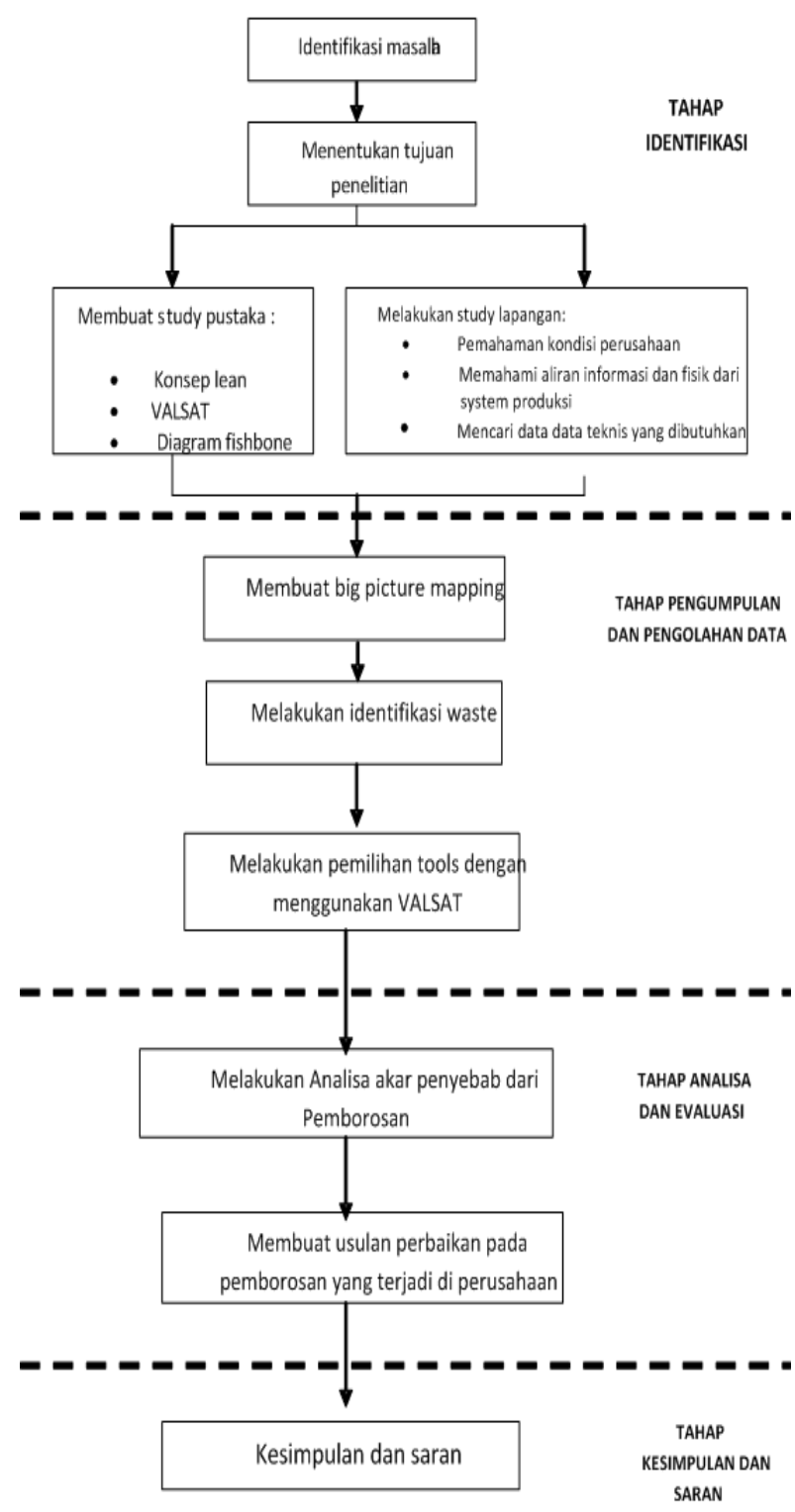


Big picture Mapping Instalasi Ngagel III PDAM SURABAYA

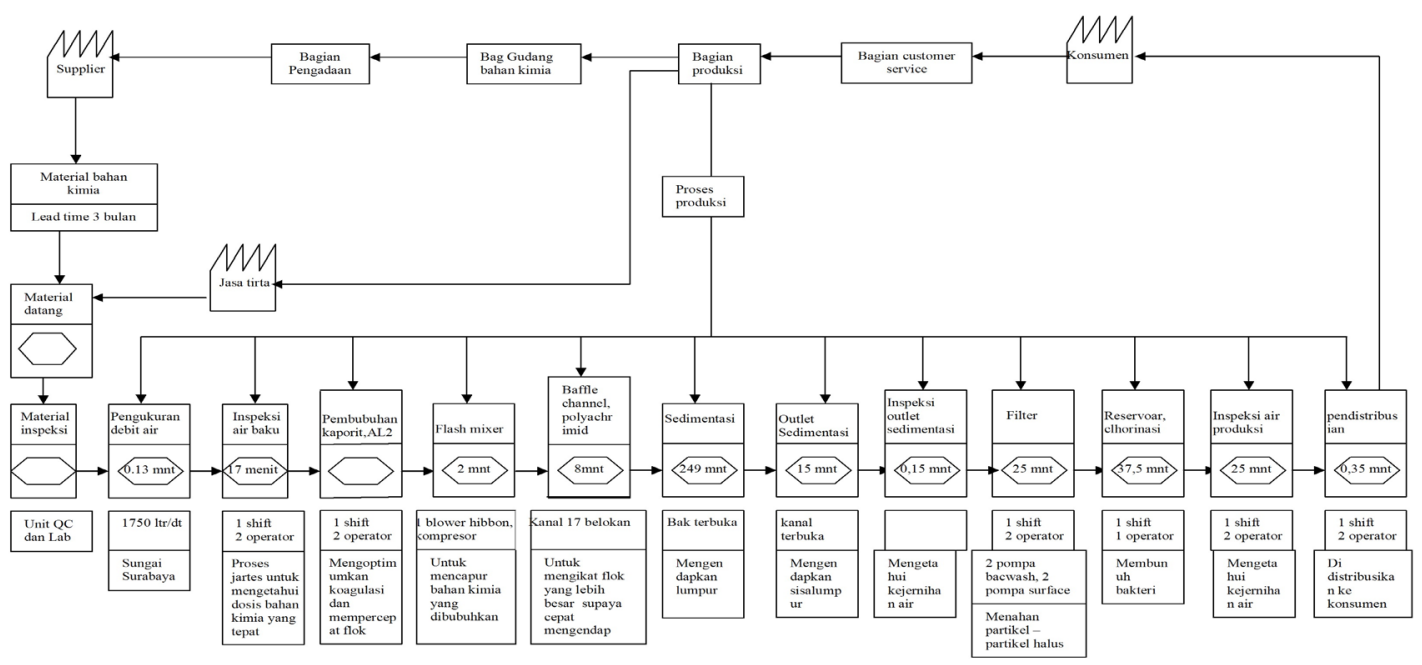

Gambar 1. Big picture Mapping proses produksi Instalasi penjernihan Ngagel III

\section{Identifikasi Pemborosan}

Proses yang tidak sesuai (Waste inappropriate processing)

- Adanya perbedaan metode kerja antar operator. Hal ini disebabkan pada proses produksi air minum PDAM, SOP (standart operational procedure) tidak pernah diperbaharui atau ter up-to-date sejak pertama kali dibuat sehingga proses produksi yang dilakukan tidak efisien.

- Di IPAM Ngagel III tidak ada proses prasedimentasi

- Pompa dan peralatan yang tidak sesuai baik kapasitas maupun kemampuannya.

Waktu tunggu (Waste Waiting)

Disebabkan produk menunggu operator untuk diproses atau sebaliknya, operator menunggu produk yang akan diproses

- Menunggu tenaga mekanik

- Waiting pada proses pengadaan

\section{Transportasi (Waste excessiveTransportation)}

- Seringnya aktivitas transportation oleh operator misalnya : Pemeriksaan kelaboratorium, Pengambilan Inspeksi air baku
Gerakan yang tidak perlu (Waste Unnecessary Motion)

Kondisi Unnecessary Motion merupakan kondisi kurang ergonomisnya suatu pekerjaan yang harus dilakukan oleh operator sehingga menimbulkan gerak dan usaha yang berlebih dari operator tersebut.

1. Kurangnya penerangan di filter

2. Kurangnya penerangan di bak sedimentasi

Cacat (Waste defects)

Cacat adalah mengidentifikasi permasalahan kualitas mutu air Perusahaan Daerah Air Minum Kota Surabaya. Kualitas air minum PDAM dapat dilihat dari:

1. Turbidity

2. Sisa Chlor Cair

Persediaan yang tidak perlu (Waste Unnecessary Inventory)

Waste ini terjadi karena persediaan yang berlebih baik raw material maupun finished good. Persediaan di IPAM Ngagel III adalah persediaan bahan kimia yang sudah tidak digunakan lagi, misalnya pada aluminium sulfat bongkahan dan karbon aktif 


\section{Hasil Kuisioner}

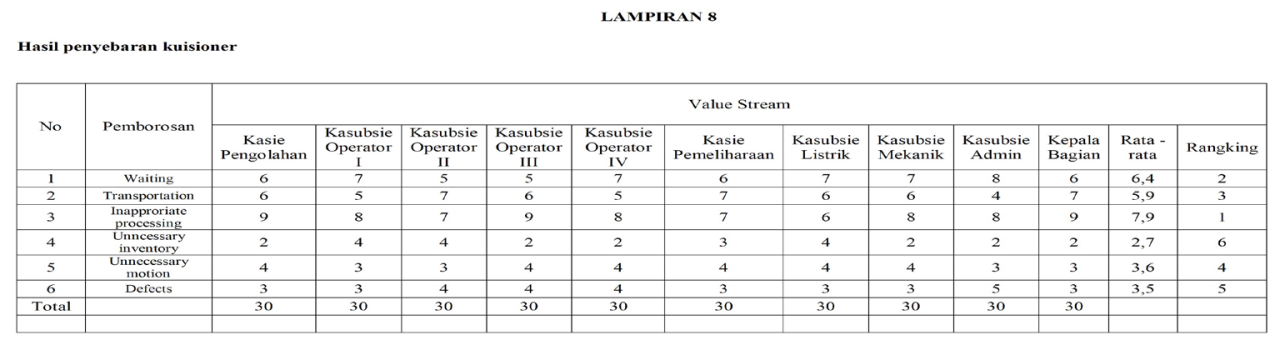

Tabel 1. Hasil Kuisioner

\begin{tabular}{|c|l|c|c|}
\hline No & Pemborosan & Nilai & Ranking \\
\hline 1 & Waiting & 6.4 & 2 \\
\hline 2 & Excessive Transportation & 5.9 & 3 \\
\hline 3 & Inappropriate Processing & 7.9 & 1 \\
\hline 4 & Unnecessary Inventory & 2.7 & 6 \\
\hline 5 & Unnecessary Imotion & 3.9 & 4 \\
\hline 6 & Defects & 3.5 & 5 \\
\hline
\end{tabular}

\section{Diagram Fishbone}

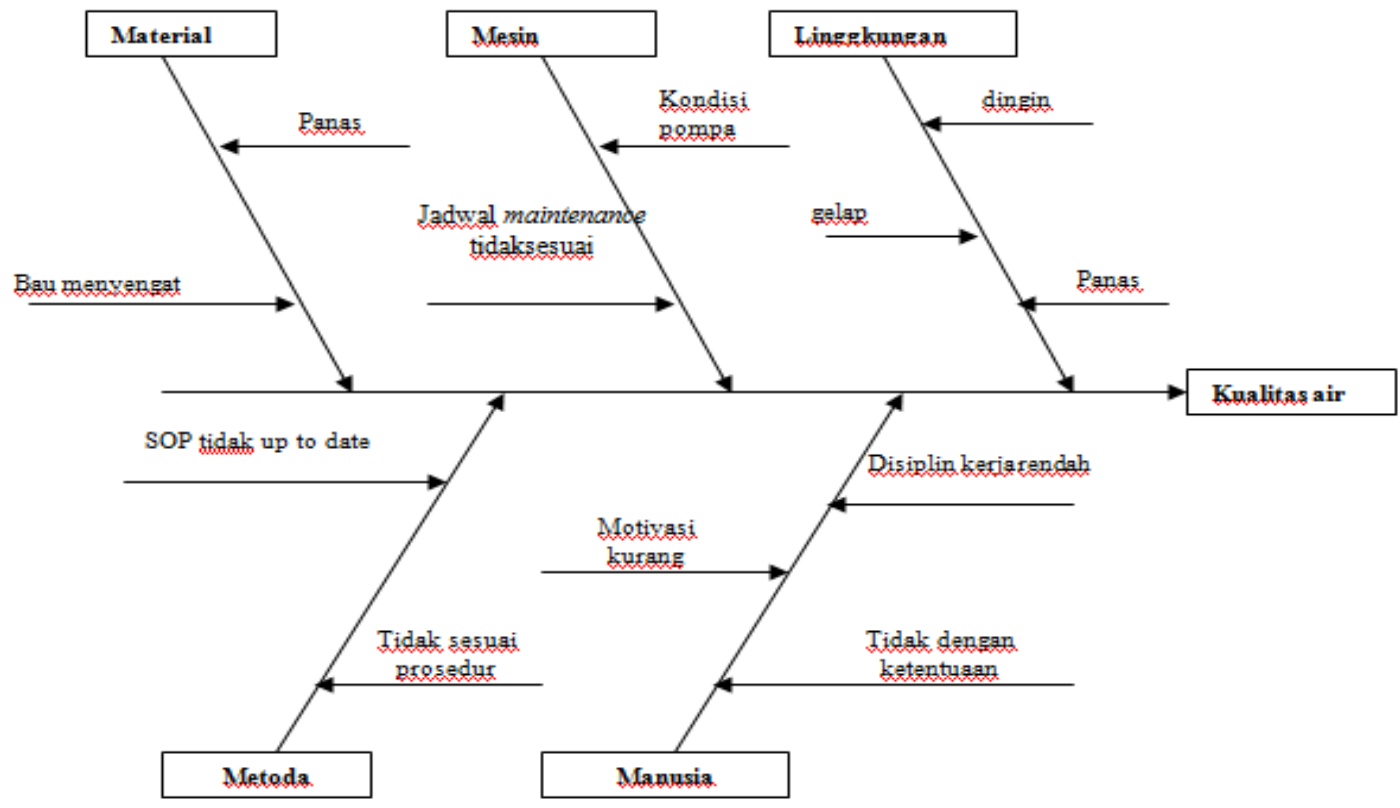

Adapun penjelasannya adalah :

- Dari kelima faktor diatas, mesin (pompa) dan manusia merupakan faktor terbesar penyebab waste inappropriate processing. Dimana mesin (pompa) dan manusia merupakan hal yang paling penting dalam proses produksi air minum di IPAM Ngagel III. Hal ini disebabkan kondisi pompa yang tidak lagi sesuai dengan kapasitasnya dan maintenance-nya tidak berjalan sebagaimana mestinya. Sedangkan pada manusia disebabkan kurangnya motivasi, disiplin kerja yang kurang dan pengerjaan tidak sesuai dengan ketentuan.

- Dari kelima faktor diatas, mesin (pompa), manusia dan metode merupakan factor yang terbesar penyebab waste defect. Hal ini disebabkan karena alat-alat yang digunakan tidak dapat digunakan seperti jartest, turbidity analyzer, pengukur sisa chlor cair, surface wash arm. Pada manusia disebabkan kurangnya motivasi, disiplin 
kerja yang kurang dan pengerjaan tidak sesuai dengan ketentuan. Sedangkan

\section{Pemilihan Tool}

dengan prosedur karena pada IPAM Ngagel III tidak ada proses prasedimentasi.

Tabel 2. VALSAT (value stream analysis tool)

\begin{tabular}{|l|l|l|l|l|l|l|l|}
\hline Waste Structure & PAM & SCRM & PVF & QFM & DAM & DPA & PSM \\
\hline Overproduction & L & M & & L & M & M & \\
\hline Waiting & H & H & L & & M & M & \\
\hline Transport & $\mathrm{H}$ & & & & & & L \\
\hline $\begin{array}{l}\text { In - a p p o p r i a t e } \\
\text { processing }\end{array}$ & $\mathrm{H}$ & & $\mathrm{M}$ & $\mathrm{L}$ & & $\mathrm{L}$ & \\
\hline Unnecessary inventory & $\mathrm{M}$ & $\mathrm{H}$ & $\mathrm{M}$ & & $\mathrm{H}$ & $\mathrm{M}$ & $\mathrm{L}$ \\
\hline Unnecessary motion & $\mathrm{H}$ & $\mathrm{L}$ & & & & & \\
\hline Defect & $\mathrm{L}$ & & & $\mathrm{H}$ & & & \\
\hline
\end{tabular}

$\mathrm{H}$ (High correlation and usefulness)

M (Medium correlation and usefulness)

L (Low correlation and usefulness)
$:$ Faktor penggali $=9$

: Faktor penggali $=3$

: Faktor penggali $=1$

Tabel 3.Hasil Valsat

\begin{tabular}{|c|c|c|c|c|c|c|c|}
\hline \multirow{2}{*}{\multicolumn{8}{|c|}{$\begin{array}{l}\text { Waste Structure } \\
\text { Overproduction }\end{array}$}} \\
\hline & & & & & & & \\
\hline Waiting & 57,6 & 57,6 & 6,4 & & 19,2 & 19,2 & \\
\hline Transport & 53.1 & & & & & & 5,9 \\
\hline $\begin{array}{l}\text { n - a propriate } \\
\text { processing }\end{array}$ & 71,1 & & 23,7 & 7,9 & & 7,9 & \\
\hline Unnecessary inventory & 8,1 & 24,3 & 8,1 & & 24,3 & 8,1 & 2,7 \\
\hline Unnecessary motion & 35,1 & 3.9 & & & & & \\
\hline $\begin{array}{l}\text { Defect } \\
\text { Total } \\
\text { Rangking }\end{array}$ & $\begin{array}{l}3,5 \\
228,5 \\
1\end{array}$ & $\begin{array}{l}85,5 \\
2\end{array}$ & $\begin{array}{l}38,2 \\
5\end{array}$ & $\begin{array}{l}31,5 \\
39,4 \\
4\end{array}$ & $\begin{array}{l}43,5 \\
3\end{array}$ & $\begin{array}{l}35,2 \\
6\end{array}$ & $\begin{array}{l}6,6 \\
7\end{array}$ \\
\hline
\end{tabular}

Berdasarkan tabel 3 bahwa tool yang terpilih menjadi alat untuk melakukan detailed mapping adalah Process Activity Mapping, dengan nilai sebesar 228,5

\section{Analisa Pemborosan Berdasarkan Process Activity Mapping}

Berdasarkan hasil process activity mapping aliran fisik proses produksi diketahui ada lima jenis aktivitas yang dapat diidentifikasikan dalam process activity mapping ini, dimana dari kelima jenis aktivitas tersebut dapat digolongkan menjadi tiga kategori. Jenis aktivitas yang masuk dalam kategori value added adalah operation, aktivitas yang masuk dalam kategori necessary but non value added activity adalah inspection, sedangkan aktivitas yang tergolong non value adding activity adalah transportation,storage dan delay. Dari 89 aktivitas Beradasarkan waktu yang digunakan dalam Process Activity Mapping, didapatkan total kebutuhan waktu selama 802.481 menit secara keseluruhan untuk menghasilkan produksi air minum di IPAM Ngagel III. Dari keseluruhan waktu tersebut terdapat sebesar 509.341 menit untuk aktivitas value adding activities atau sekitar $63.47 \%$ dari total waktu. Sedangkan untuk waktu yang dibutuhkan untuk melakukan necessary but non value added activity selama 27.855 menit atau sebesar $3.47 \%$ dari keseluruhan total, dan waktu non value adding activities membutuhkan waktu selama 265.285 menit atau sekitar $33.06 \%$ dari total waktu.

Tabel 4. Waktu tiap aktivitas pada IPAM Ngagel III

\begin{tabular}{|c|c|c|c|c|c|}
\hline & Operasi & Transport & Inspeksi & Storage & Delay \\
\hline Jumlah aktivitas & 38 & 33 & 18 & 0 & 0 \\
\hline $\begin{array}{l}\text { Jumlah } \quad \text { waktu } \\
\text { aktivitas }\end{array}$ & 509.341 & 265.285 & 27.855 & 0 & 0 \\
\hline Prosentase & $63.47 \%$ & $33.06 \%$ & $3.47 \%$ & $0.00 \%$ & $0.00 \%$ \\
\hline
\end{tabular}




\section{Rekomendasi Perbaikan}

Dari analisa pemborosan yang telah dilakukan, diberikan beberapa rekomendasi untuk meminimasi pemborosan yang terjadi pemborosan antara lain:

- Instalasi Ngagel III membuat SOP (Standart operational Procedur) yang baru.

- Memperbaiki jadwal maintenance.

- Memfungsikan kembali system otomatisasi sludge drain.

- Melakukan tindakan preventif maintenance untuk keseluruhan pompa dan peralatan serta melakukan pergantian sparepart pada peralatan yang rusak sehingga dapat memaksimalkan kemampuan proses produksi.

- Melakukan pembelian pompa baru atau pengadaan suku cadang pompa yang sangat vital

- Memperketat aturan serta memberikan sanksi bagi yang tidak mematuhi.

- Perbaikan dan pembelian alat yang lebih baik seperti untuk mengetahui sisa chlor cair, jartest, surface wash arm, buka tutup valve, turbiditimeter.

- Waktu proses pengadaan dipercepat.

- Perbaikan pompa inspeksi air baku.

- Lampu penerangan di bak sidementasi dan filter diperbaiki sehingga bisa dinyalakan pada malam hari.

- Melakukan perencanaan ulang apabila melakukan pemesanan bahan kimia.

- Menggunakan bahan kimia sampai habis.

\section{KESIMPULAN}

Pemborosan Perusahaan Daerah Air Minum di IPAM Ngagel III yaitu terdiri dari inappropriate processing, waste excessive transportation, waste waiting, waste unnecesarry motion, waste defects, dan waste unncessary inventory.

- Waste Inappropriate Processing, dampak yang diakibatkan adalah biaya operasional lebih tinggi, waktu proses produksi yang tidak optimal, kuantitas air atau debit air yang diproduksi berkurang, serta mempengaruhi kualitas produksi air.

- Waste Excessive Transportation, menyebabkan pemborosan pada waktu, tenaga dan biaya.

- Waste Waiting, menyebabkan terganggunya proses produksi yang menyebabkan panjangnya lead time sehingga kuantitas air yang diproduksi berkurang.

- Waste Unnecesarry Motion, menyebabkan penurunan performansi sehingga resiko kesalahan saat bekerja dan perhatian yang ekstra dari operator.

- Waste defects menyebabkan bahan kimia yang dipakai lebih banyak, banyaknya biaya operasional yang dikeluarkan

- Waste unncessary inventory menyebabkan Gudang menjadi penuh, meningkatnya biaya penyimpanan

\section{DAFTAR PUSTAKA}

Andi Supriyanto, dkk(1995). Laporan On the Job Training Di Instalasi penjernihan Ngagel III Perusahaan Daerah Air Minum Kotamadya Surabaya. Pendidikan Dan Latihan Tenaga Teknik Penyediaan Air Minum PERPAMSI, Institut Teknologi Sepuluh November, Surabaya Pujawan, I Nyoman (1995). Ekonomi Teknik. Surabaya : Prima Printing

Pujawan, I nyoman (2005), Supply Chain Management, Edisi Pertama, Guna Widya, Surabaya

Santika, Sri Simestri (1984). Metode Penelitian Air. Usaha Nasional, Surabaya.

Stoner. A.F. janes., Freeman Edward R., Gilbert JR. R. Daniel. (1996), Manajemen, jilid 1, PT Indeks, Gramedia Grup, Jakarta Barat.

Sugiharto, (1987), Dasar-Dasar Pengelolaan Air Limbah, UI Press Jakarta.

Taylor, D and Brunt, D (2001). Manufacturing Operations and Supply Chain Management : the Lean Approach. Thomson Learning, London

Wardhana Arya Wisnu, (1995), Dampak Pencemaran Lingkungan, Andi Offset Yogyakarta

Wignjosoebroto, Sritomo (1995). Ergonomi, Studi Gerak Dan Waktu. Guna Widya, Jakarta. 